Part of Journal of Research of the National Bureau of Standards, Volume 23, November 1939

\title{
COSMIC-RAY OBSERVATIONS IN THE STRATOSPHERE WITH HIGH-SPEED COUNTERS
}

\author{
By Leon F. Curtiss, Allen V. Astin, Leroy L. Stockmann, and Burrell W. Brown
}

\section{ABSTRACT}

By a modification of a method ${ }^{1}$ reported previously, observations of cosmic-ray intensity at high altitudes have been made.

A Neher-Harper circuit has been used with relatively large Geiger-Müller counters so that 2,000 to 3,000 counts per minute could be recorded by means of radio equipment sent aloft attached to free balloons. The counters were standardized in terms of the radiation from $1 \mathrm{mg}$ of radium at a distance of $1 \mathrm{~m}$, and the maximum cosmic-ray intensity was found to be 0.55 percent of this intensity. This maximum was found to occur at an atmospheric pressure of 60 millibars. A very low intensity at pressures of about 5 millibars, reported in the previous paper, was not observed in any of the 15 ascents in which the data reported in the present paper were obtained.

\section{CONTENTS}

Introduction

II. Description of balloon equipment

1. Counters . .

2. Integrating circuit.

3. Barograph $\ldots \ldots$

4. Radio transmitter

5. Batteries_...

6. Assembly _.

7. Balloons

III. Ground equipment _._. 590

IV. Results

\section{INTRODUCTION}

In a previous paper ${ }^{2}$ results were given of cosmic-ray observations in the stratosphere, using small, low-speed Geiger-Müller counters. The counters were carried aloft by sounding balloons, and the counts were broadcast to a receiving station on the ground by a radio transmitter also carried by the balloons. The active volume of each counter was approximately $1 \mathrm{~cm}^{3}$, and the counting rate at the altitude of maximum intensity was approximately 60 per minute. Since the counting rate on the ground was less than one per minute and since the time required for the equipment to reach the altitude of maximum counting rate was only 90 minutes, the results were subject to considerable statistical fluctuation.

1 Phys. Rev. 53, 23 (1938)

2 L. F. Curtiss, A. V. Astin, L. L. Stockmann, B. W. Brown, and S. A. Korff, Phys. Rev. 53, 23 (1938). 
In the present investigation the size of the counters has been increased to give approximately a thirtyfold gain in counting rate. This increase was sufficient to make the curves of counting rate versus pressure comparable in smoothness to those obtained from observations with ionization chambers. The great advantage of the counter method over the ionization chamber for cosmic-ray exploration of the upper atmosphere is that the balloons do not have to be recovered in order to obtain the data.

A further improvement in the present investigation over earlier work has been the standardization of each counter in terms of gamma radiation from radium.

\section{DESCRIPTION OF BALLOON EQUIPMENT}

\section{COUNTERS}

The general construction of the Geiger-Müller counter tubes used in this investigation may be seen in figure 1 , which shows a typical tube. The outer electrode, or cathode, is a copper tube about $1 \mathrm{~cm}$ in diameter and $16 \mathrm{~cm}$ in length. The anode is a No. 42 steel wire with glass sleeves at the ends to serve as guards, after the manner described by Cosyns and de Bruyn. ${ }^{3}$

To secure a broad and level plateau, it has been found necessary to clean the electrodes by sputtering. The treatment employed is a modification of the method described by Diffenbach, Lifshutz, and Slawsky. ${ }^{4}$

The electrodes are connected to a transformer adjusted to produce a steady glow between the electrodes in an atmosphere of hydrogen at a pressure equivalent to a few millimeters of $\mathrm{Hg}$. The hydrogen is changed frequently and the sputtering permitted to continue for from 12 to 24 hours. Care must be taken during the sputtering to prevent a deposition of metal on the glass surface so that the insulation may not be ruined.

After sputtering, the counters are filled and sealed with a mixture of about 10 parts of argon to 1 part of hydrogen at a pressure of approximately $6 \mathrm{~cm}$ of $\mathrm{Hg}$. The counters so treated and filled require about 575 volts for their operation and have an approximately constant counting rate for any voltage, either higher or lower, within 50 volts of this value.

\section{INTEGRATING CIRCUIT}

The wiring diagram of the amplifier and integrating circuit associated with the counter is shown in figure 2 . The pulses from the counter are fed to a high-speed stage of the Neher-Harper ${ }^{5}$ type.

The major purpose of this stage is to restore rapidly the counter to its normal state. The second stage serves to level the pulses, since those coming from the first stage may have widely different magnitudes. The tube is arranged for a sharp cut-off, so that all input pulses, regardless of their magnitude, give the same output signal. The third stage rectifies the pulses and the rectified current charges the capacitor, $C_{4}$. When the charge on $\mathrm{C}_{4}$ is sufficient to flash the neon tube, $N$, a signal is transmitted through the final stage, actuating

Acad. roy. Belg., Bul. classe sci. 20, 271 (1934).

1 Phys. Rev. 52, 1231 (1937).

o Phys. Rev. 49,940 (1936). 


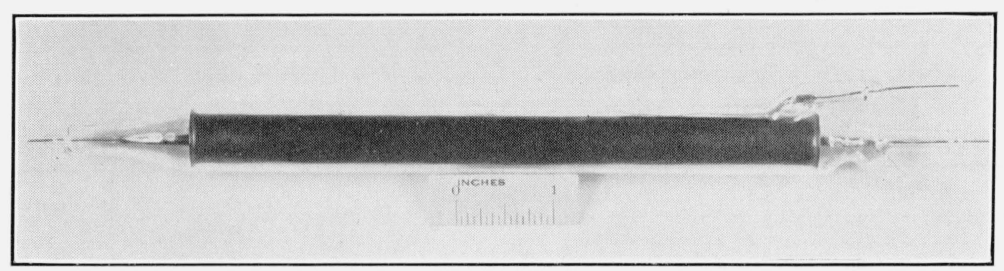

FigURE 1.-Geiger-Müller tube counter used with radio-balloon equipment. 
the relay, $Z$. The relay is arranged to key the radio transmitter. The flashing voltage of the neon tube and the size of capacitor $\mathrm{C}_{4}$, as well as the magnitude of the leveled pulses, determine the number of counts or discharges in the Geiger-Müller tube necessary to actuate the relay. This number has varied from 35 to 100 in the 15 units that have been used for stratosphere soundings.

The integrating circuit, which is similar in some respects to one described by Johnson, ${ }^{6}$ is essential to prevent a large increase in the keying rate of the transmitter when the counting rate is stepped up. This is because of speed limitations of the ground recording system. In the earlier work of the authors with low-speed counters the integrating circuit was not essential. It was found that with the amplifying and integrating circuit of figure 2, higher counting rates could be handled than could be provided with counters of the size described

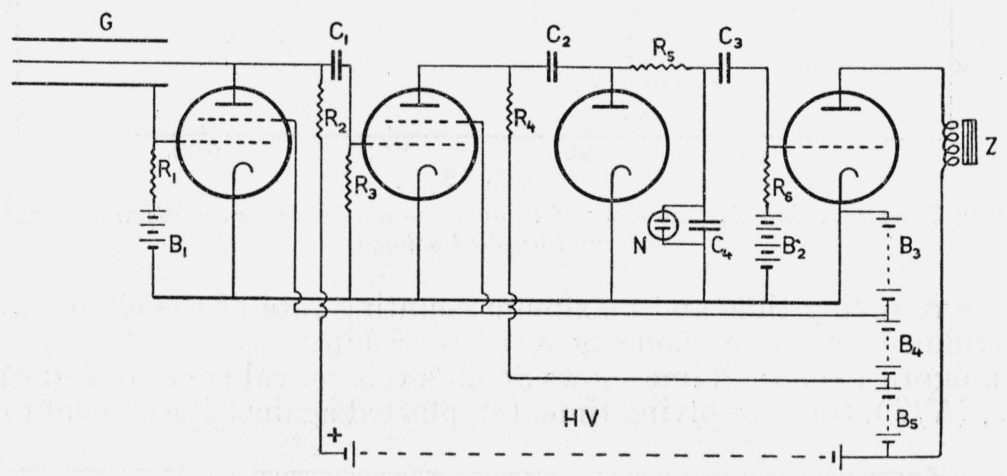

FIGURE 2.-Wiring diagram of integrating circuit used with tube counters.

$\begin{array}{ll}G=\text { tube counter } & \\ C_{1}=0.0001 \mu \mathrm{f} & R_{1}=20 \text { megohms } \\ C_{2}=0.0001 \mu \mathrm{f} & R_{2}=5 \text { megohms } \\ C_{3}=0.01 \mu \mathrm{f} & R_{3}=1 \text { megohm } \\ C_{4}=0.01 \mu \mathrm{f} . & R_{4}=1 \text { megohm } \\ & R_{5}=20 \text { megohms } \\ R_{6}=10 \text { megohms }\end{array}$

in the previous section. Accordingly two counters were connected in parallel, thus approximately doubling the counting rate.

The characteristic of a typical counter and its associated circuit as a function of voltage applied to the counter is shown by figure 3 . The fact that the counting rate is constant over a 95-volt range shows that not only does the counter have a satisfactory plateau but that the leveling stage of the amplifier is operating satisfactorily. Tests of the linearity of the integrating circuit have been made in three different ways with equally satisfactory results in each case. With different intensities of radiation applied to the counter, the flashing rates have been compared to the counting rates of a Cenco counter connected directly to the output of the first stage of the amplifier so as to record the impulses of the counter directly. The number of impulses per flash was the same for all counting rates tested. The second test consisted in placing radium samples of different known intensities at a fixed distance from the counter tube. The ratios of the differences in counting rates were the same as ratios of the differences in

\footnotetext{
- Phys. Rev. 53, 914 (1938).
} 
strengths of radium sources. The third test involved a fixed quantity of radium at different distances from the counter. The ratios of the differences in counting rates coincided with the expected differences from inverse-square law calculations.

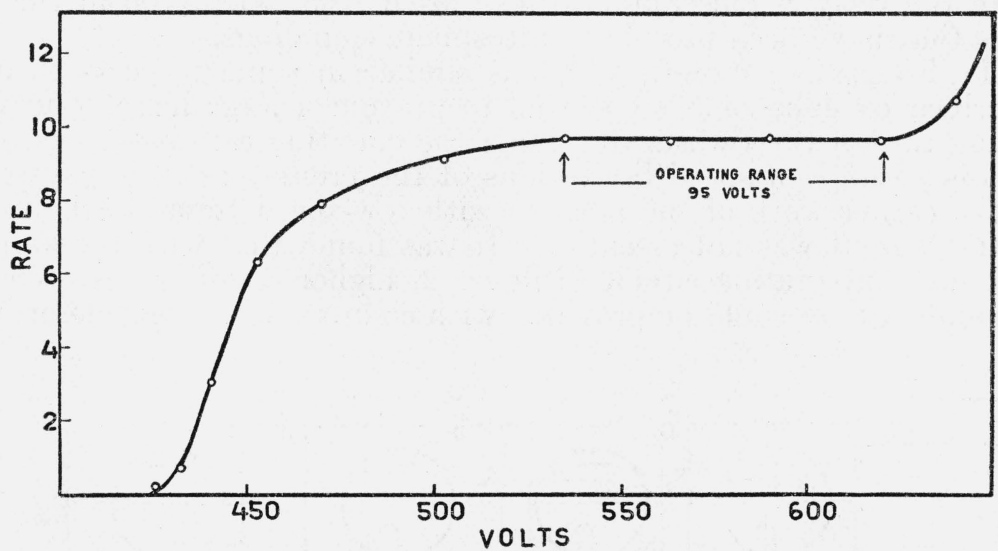

FIGURE 3.-Operating characteristic of typical counter showing variation of counting rate with applied voltage.

The resolving time and maximum counting rate of the circuit were determined by the method suggested by Schiff. ${ }^{7}$

In figure 4 the solid line shows Schiff's theoretical curve of counting rate, $(N / T)$, times resolving time, $(\tau)$, plotted against the ratio of total

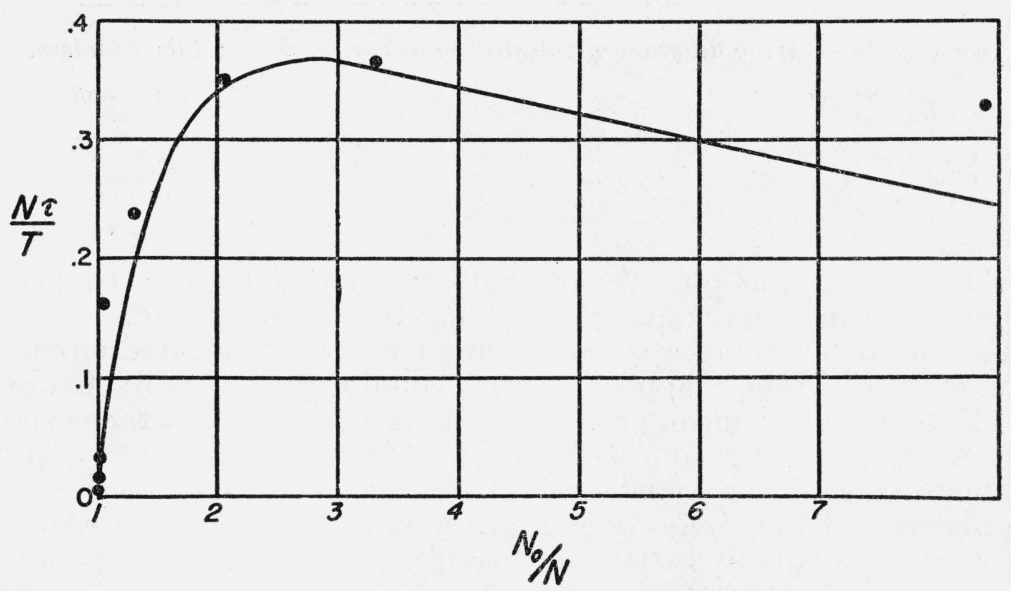

FIgURE 4.-Efficiency characteristic of counter circuit.

$N=$ Total number of pulses counted in time $T$.

$N_{0}=$ Total number of pulses in counter in time $T$. $\tau=$ Resolving time of circuit.

particles through the counter, $\left(N_{0}\right)$, to the number recorded by the counter, $N$. The maximum counting rate occurs when $N_{0} / N=e$ and the resolving time is determined from the value of the maximum, $N \tau T / T=1 / e$. The circles show the experimental points which were

\footnotetext{
7 Phys. Rev. 50, 88 (1936).
} 


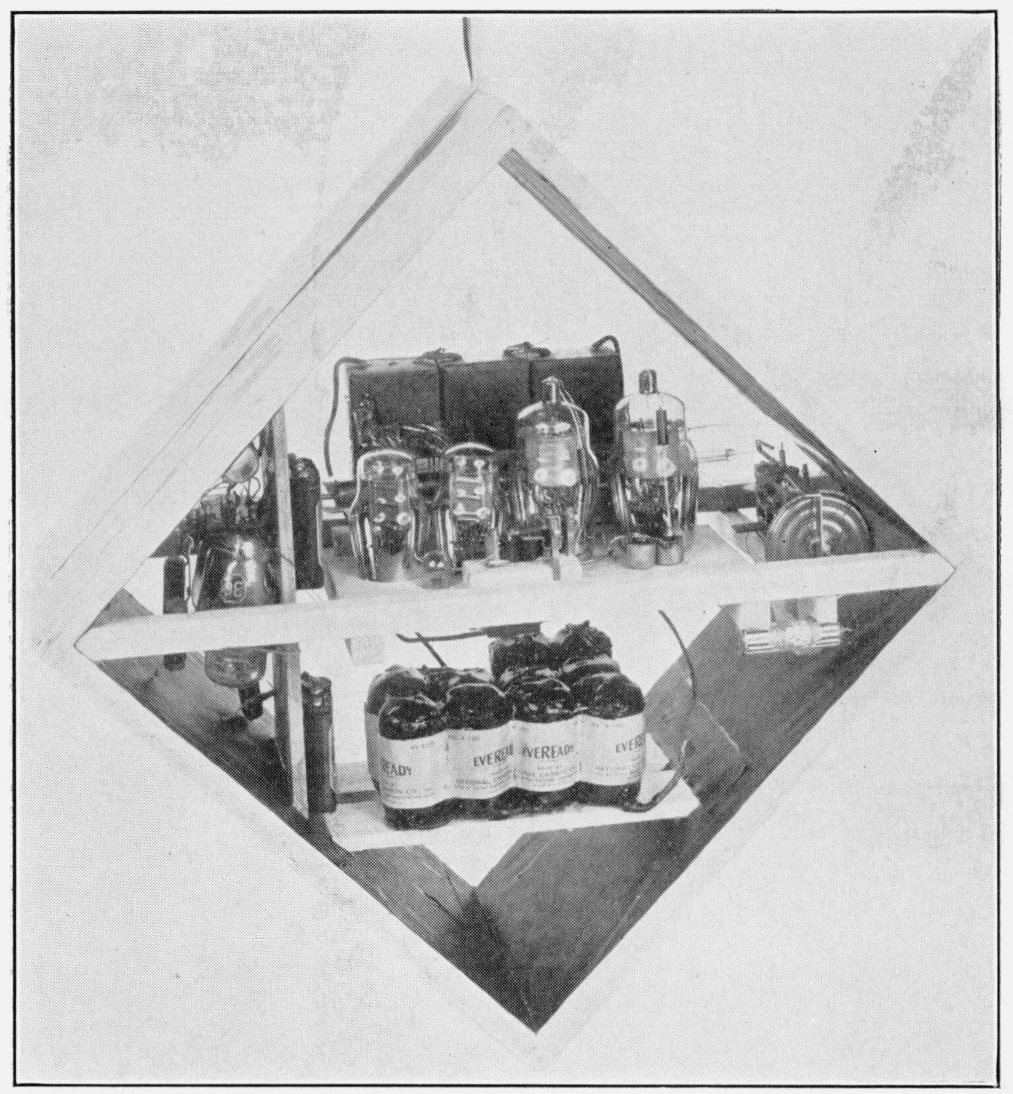

FIGURE 5.-Complete assembly including counter tubes, vacuum-tube circuit, barograph, radio transmitter, and necessary batteries. 


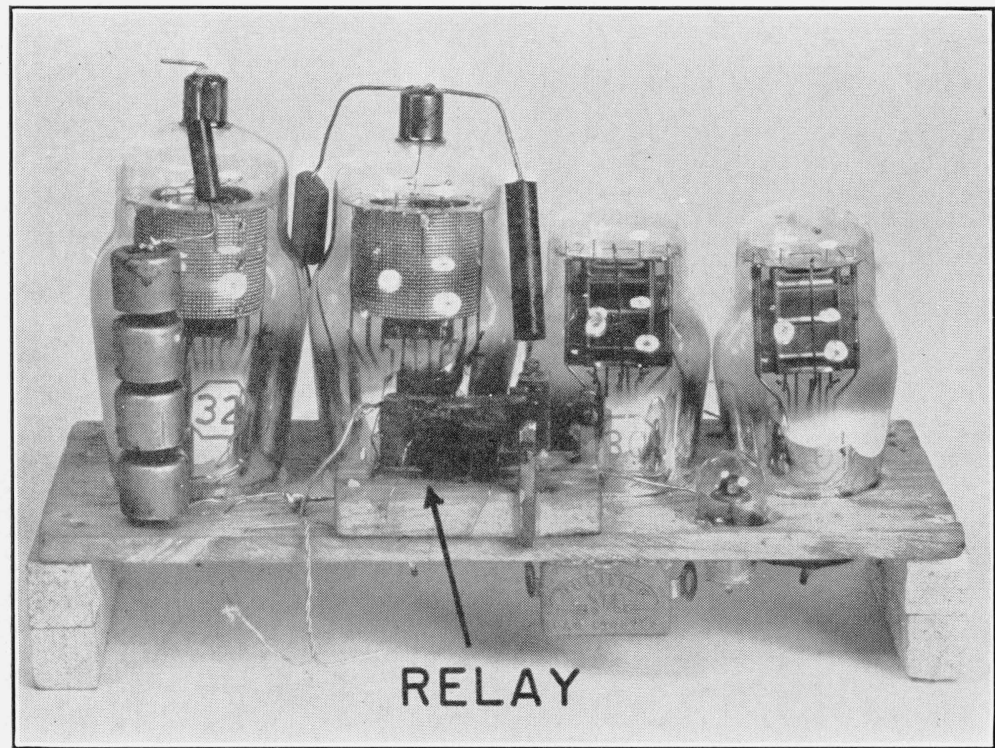

FigURE 6.-Amplifying and integrating assembly. 
obtained by observing the counting rates when radium sources of different known intensities were placed at a fixed distance from the counter. The values of $N_{0}$ were fixed from the lower counting rates where a linear welation was observed between counting rate and intensity of the source (after allowing for the blank counting rate). Theory and experiment show the maximum counting rate at the same value of $N_{0} / N$, but differ in other respects, as shown in the figure. These differences might occur if the resolving time, $\tau$, were not constant, as was assumed by Schiff. The value obtained for $\tau$ from this set of data was $9 \times 10^{-4}$ second. In the observations on cosmic rays the counting rates never exceeded a value for $N \tau / T$ of 0.05 , for which values $N_{0} / N$ was unity, within a few percent.

\section{BAROGRAPH}

The barograph used in this investigation was of the same type as that used in the earlier work and has been described in detail elsewhere. ${ }^{8}$ The sensitive element of the barograph was a small aneroid capsule of copper-beryllium alloy. The revolving contact arm of the barograph was driven by a small impulse-type motor which was adequately powered by a 11/2-volt "pen-light" battery. Pressures could be determined to within \pm 2 millibars over the range of pressures 1,000 to 5 millibars. The possible error due to temperature variations of the barograph has been carefully investigated and found to be less than the precision of reading over the entire range.

\section{RADIO TRANSMITTER}

The radio transmitter was also the same as that used in the earlier work. It consisted of two type 30 tubes in push-pull oscillating at 55.5 megacycles and powered by a 135-volt plate supply. Keying was accomplished by short-circuiting a cathode biasing resistor. The resistor was sufficiently large so that the circuit would not oscillate unless the resistor were shorted. Consequently, the transmitter was silent except for the relatively short times of keying, an important factor in keeping the battery requirements at a minimum.

\section{BATTERIES}

The voltage supply for the counter (B5, fig. 2) was obtained from Eveready X-180 units. Each one of these units supplies 45 volts and weighs but 2 ounces. The plate voltage for the tubes of the amplifier, as well as for the transmitter, was obtained from Burgess V40 $\mathrm{Fl}$ units. Each of these units furnishes 45 volts and weighs about 3.5 ounces. The filaments of all tubes required 2 volts for their operation, which was obtained from ordinary flashlight batteries. It was found most convenient to connect two filaments in series and heat them with the current from three flashlight batteries in series.

\section{ASSEMBLY}

The assembled balloon equipment is shown in figure 5. The four tubes of the amplifier and integrating circuit, a separate view of which is shown in figure 6 , are in the center of the picture. The plate-supply

\footnotetext{
8 Phys. Rev. 53, 23 (1938); J. Research NBS 22, 97 (1939) RP1169.
} 
batteries for these tubes, as well as for the transmitter, are just behind them. In front of the amplifier are the neon tube and relay ( $Z$, fig. 2 ) for keying the transmitter. The second counter has been removed but is normally installed just in front of the amplifier. Below the amplifier may be seen the high voltage supply for the counters. To the right of the amplifier is the barograph unit, and to the left is the radio transmitter. The antenna and attachment cord to the balloons are shown in the upper part of the picture.

The crate in which the equipment is mounted consists of a balsawood frame with double Cellophane lining for heat insulation. The front and back sides of the crate are removed in figure 5. The interior Cellophane surface is lined with black paper, which serves both as a heat absorbing surface and as a light shield for the counters. Tests on the interior temperatures of such enclosures when in the stratosphere in daytime have shown the temperature to be within $\pm 15^{\circ} \mathrm{C}$ of $25^{\circ} \mathrm{C}$.

It was found that moisture enclosed within the frame when the crate was sealed frequently condensed on parts of the insulation and interfered with the proper operation of the equipment. This trouble was eliminated by coating the insulating surfaces well with Superla wax and enclosing some calcium chloride in a cheesecloth bag within the crate when it was sealed.

The weight of the completely assembled balloon equipment ready for attaching to the balloons was approximately $2,200 \mathrm{~g}$.

\section{BALLOONS}

The counter equipment and radio transmitter were carried aloft by five or six Dewey and Almy latex balloons, model No. 700. These balloons have an uninflated diameter of about $4 \mathrm{ft}$ and will expand to approximately $19 \mathrm{ft}$ before bursting. The balloons were inflated with hydrogen to have a free lift of approximately $600 \mathrm{~g}$ per balloon. This gave an ascension rate in excess of that normally used in stratosphere soundings, but it has been the authors' experience that higher altitudes are obtained with higher ascensional rates.

The balloons were attached to strings of different lengths to reduce contact of the balloons with each other. This was found desirable in preventing both premature and simultaneous bursting of the balloons.

\section{GROUND EQUIPMENT}

The receiver used in this work was a commercial 5-meter superregenerative type. A detector tube of the grid current type was added to the receiver. In its unexcited condition the regenerative noise of the receiver suppressed the plate current of the detector tube. A signal entering the receiver suppressed the regenerative noise and caused an increase in the current of the detector tube. The receiver was very insensitive to noise, since only a definite pulse of waves of the frequency to which the receiver was tuned would suppress the regenerative noise and thus release the output current. Ordinary static was quite ineffective, since it mainly added to the regenerative noise. The disadvantage of the circuit was that a signal of at least about one-tenth second duration was necessary to actuate the receiver. This, of course, limits the number of signals per second which the 
receiver can handle and explains why it was essential to use an integrating circuit on the balloon equipment for high-speed counters.

The method of actuating the recorder is shown in figure 7 . The plate current from the detector tube enters at the terminals marked "to amplifier" and passes to the relay. A signal in the receiver increases the current through the meter, $M$, and actuates the relay, which in turn controls the grid potential of the gas-filled 885 triode. The plate current of the 885 tube passes through an electromagnet which controls a recording stylus.

The complete ground equipment is shown in figure 8. The receiver is to the right; the plate-current meter of the detector circuit, the 885 tube, and the power supply are in the center; and the waxed-tape record and recording stylus to the left. Perforated tape, moved by a sprocket which is driven by a synchronous motor, is used to secure uniform motion of the tape.

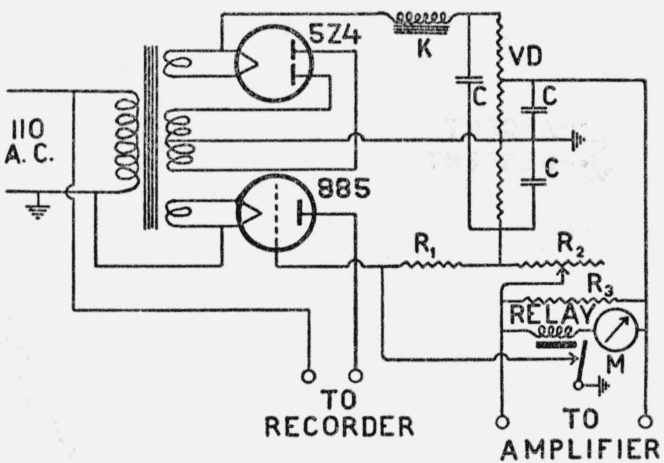

FIgURE 7.-Wiring diagram of detector circuit used with superregenerative receiver to actuate records.

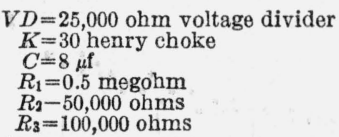

A sample record is shown in figure 9. The upward breaks in the horizontal line on the tape correspond to signals received from the radio transmitter. The double breaks marked "reference doublet". correspond to regular keyings of the transmitter by the motor-driven contact arm. These reference marks are received approximately four times per minute. The break marked "pressure" corresponds to a keying of the contact arm by a contact point connected to the aneroid capsule. The ratio of the distance between a reference doublet and pressure signal to the distance between two reference doublets gives a measure of the pressure. The narrow breaks in the horizontal line marked "cosmic rays" correspond to keyings of the transmitter by the integrating circuit. These signals are readily discernible from the barograph signals by both their width and position. The regularity of the spacing between the cosmic-ray signals is an indication of the extent to which the random fluctuations in the individual discharges of the counter are smoothed out by the integrating circuit. 


\section{RESULTS}

A total of 15 successful sets of observations were obtained with equipment of the type just described, between July and November 1938. A typical record, which was obtained July 22, is shown in figure 10. The record shows excellent agreement in results obtained during both the ascent and descent of the balloons. The ordinate scale shows the actual number of discharges per minute in the counters, which for this particular equipment was 48 times the flashing rate of the neon tube in the integrating circuit, or 48 times the number of cosmic-ray radio signals received at the ground station. The number of counts required to flash the neon tube was determined by means of a Cenco counter.

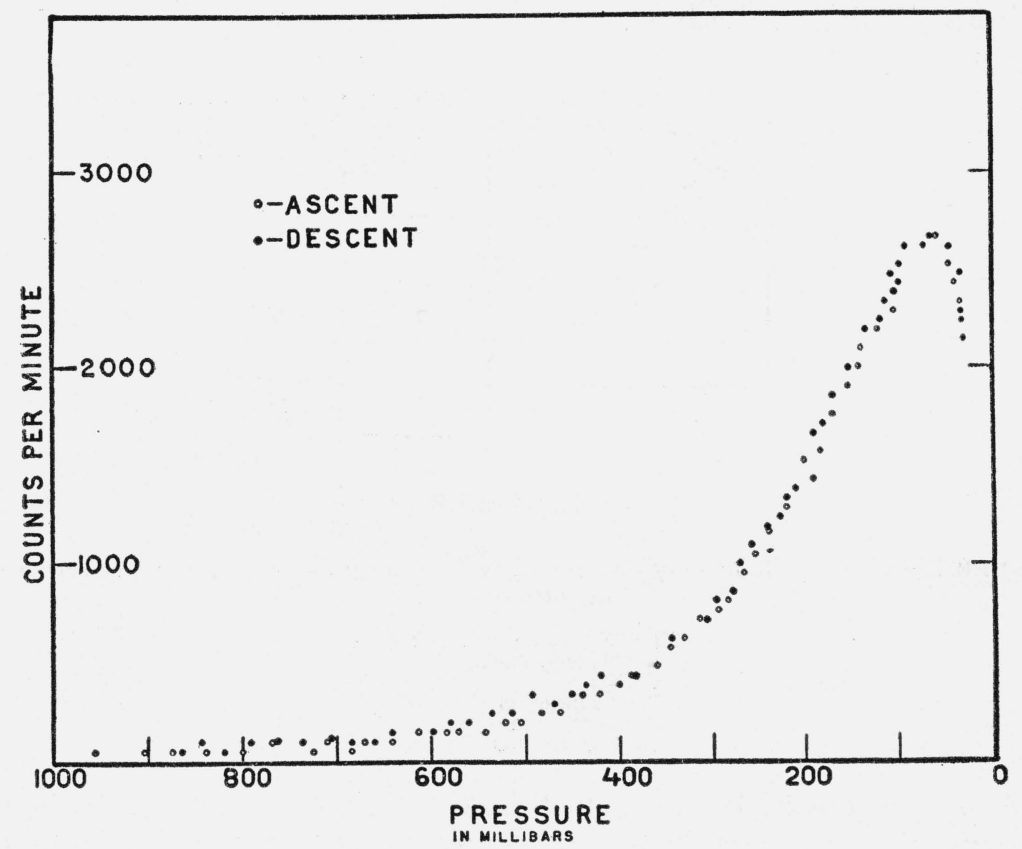

FigURE 10.-Data obtained on a single ascent and descent, showing counts per minute plotted against the atmospheric pressure in millibars.

A summary of all the results obtained is given in table 1. Column 1 of the table gives the date on which the observations were made, and column 2 gives the number of counts necessary to flash the neon tube of the integrating circuit. Column 3 shows the number of counts produced in each set of equipment by $1 \mathrm{mg}$ of radium placed $1 \mathrm{~m}$ from the counters. Although the counters were made as nearly alike as was reasonably possible, there are evidently real differences in the sensitivities of the counters. These differences are made apparent by comparing the standard deviation of the values of column 3 from their mean with the deviation one would expect if an equivalent number of observations were taken with a single counter under constant conditions. The expected standard deviation of a single observation of $N$ events, distributed at random (that is, according to 


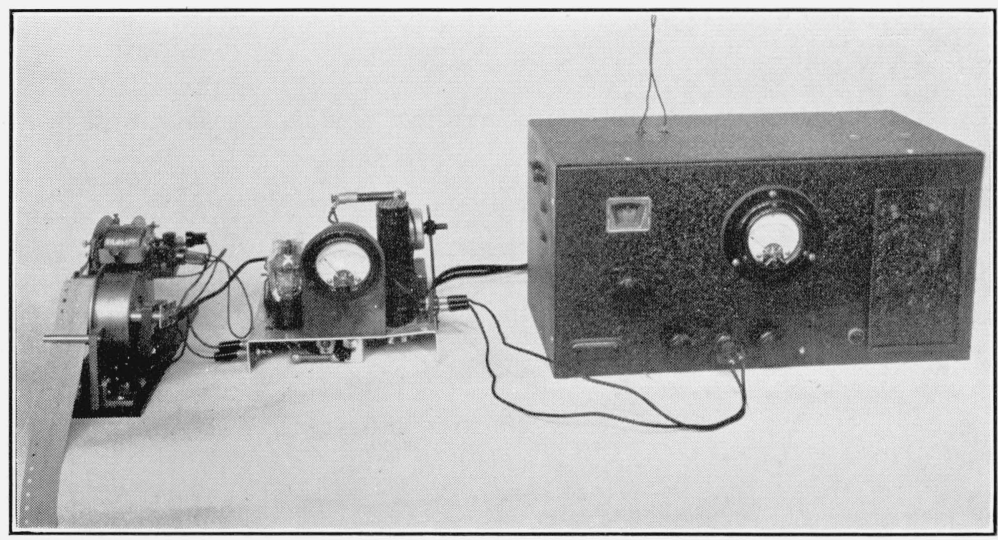

FiguRE 8.-Complete receiving equipment.

The superregenerative receiver is on the right. The detector circuit operated by the output of the receiver is in the center. The tape recorder is on the left.

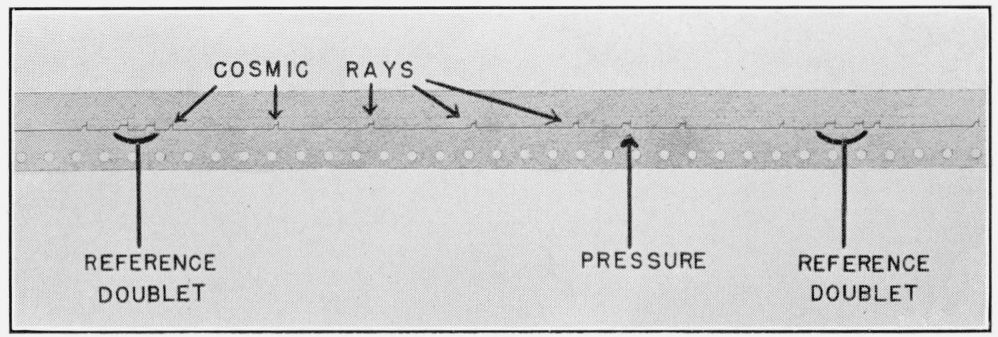

Figure 9.-Sample of actual record on waxed tape. 
Poisson's law), is $N^{1 / 2}$. The total number of events or counts involved is $3,320 \times 15 \times 5=249,000$ (since each of the 15 values in the table represents the average over 5 minutes). The expected standard deviation of this value would be 498 for the 75 -minute period, which would give an expected, standard deviation of 7 , in the average counting rate, per minute. This expected value of 7 for a single counter is so much less than the actual standard deviation, 110 , of the 15 counters, from their mean that there is little doubt that real differences exist in the sensitivities of the counters.

TABLE 1.-Summary and analysis of observations

\begin{tabular}{|c|c|c|c|c|c|c|c|c|c|c|}
\hline $\begin{array}{c}\text { Date } \\
(1938)\end{array}$ & $\begin{array}{l}\text { Average } \\
\text { counts } \\
\text { per } \\
\text { signal }\end{array}$ & $\begin{array}{c}\text { Stand- } \\
\text { ardiza- } \\
\text { ticn, } \\
\text { counts } \\
\text { per } \\
\text { menute } \\
\text { for } 1 \mathrm{mg} \\
\text { of Ra at } \\
1 \mathrm{~m} \\
\\
3\end{array}$ & $\begin{array}{c}\text { Maxi- } \\
\text { mum } \\
\text { obses ved } \\
\text { count- } \\
\text { ing rate } \\
\text { in upper } \\
\text { atmos- } \\
\text { phere, } \\
\text { counts } \\
\text { per } \\
\text { min. } \\
\text { ute } \\
4\end{array}$ & $\begin{array}{l}\text { Pres- } \\
\text { sure at } \\
\text { altitude } \\
\text { ol maxi- } \\
\text { mum } \\
\text { count- } \\
\text { ing rate }\end{array}$ & $\begin{array}{l}\text { Ratio of } \\
\text { maxi- } \\
\text { mum } \\
\text { count- } \\
\text { ing rate } \\
\text { to stand- } \\
\text { ard } \\
\text { count- } \\
\text { ing rate }\end{array}$ & $\begin{array}{c}\text { Ratio of } \\
\text { count- } \\
\text { ing rate } \\
\text { at } 200 \\
\text { mb to } \\
\text { maxi- } \\
\text { mum } \\
\text { count- } \\
\text { ing rate } \\
7\end{array}$ & $\begin{array}{l}\text { Ratio of } \\
\text { count- } \\
\text { ing rate } \\
\text { at } 500 \\
\text { mb to } \\
\text { maxi- } \\
\text { mum } \\
\text { count- } \\
\text { ing rate }\end{array}$ & $\begin{array}{c}\text { Blank } \\
\text { count- } \\
\text { ing rste } \\
\text { per } \\
\text { min- } \\
\text { ute }\end{array}$ & $\begin{array}{c}\text { Pres- } \\
\text { sure at } \\
\text { maxi- } \\
\text { mum } \\
\text { altitude } \\
\text { attained }\end{array}$ & $\begin{array}{l}\text { Ratio of } \\
\text { count- } \\
\text { ing rate } \\
\text { ut maxi- } \\
\text { mum } \\
\text { altitude } \\
\text { to maxi- } \\
\text { mum } \\
\text { count- } \\
\text { ing rate } \\
11\end{array}$ \\
\hline $\begin{array}{l}7 / 13 \\
7 / 15 \\
7 / 22 \\
7 / 25 \\
7 / 28\end{array}$ & $\begin{array}{r}40.6 \\
52.0 \\
47.6 \\
40.1 \\
102.5\end{array}$ & $\begin{array}{l}3,830 \\
3,540 \\
3,240 \\
2,690 \\
2,970\end{array}$ & $\begin{array}{l}2,110 \\
2,340 \\
2,620 \\
4,1 \in 0 \\
1,540\end{array}$ & $\begin{array}{r}m b \\
60 \\
60 \\
60 \\
55 \\
60\end{array}$ & $\begin{array}{l}0.55 \\
.67 \\
.81 \\
.62 \\
.62\end{array}$ & $\begin{array}{r}0.50 \\
.62 \\
.58 \\
.62 \\
.60\end{array}$ & - & ר... & $\begin{array}{r}m b \\
15 \\
15 \\
28 \\
15 \\
\mathrm{x} 12\end{array}$ & $\begin{array}{r}0.79 \\
.91 \\
.86 \\
.76 \\
.73\end{array}$ \\
\hline $\begin{array}{l}9 / 27 \\
9 / 29 \ldots\end{array}$ & $\begin{array}{l}49.6 \\
72.8\end{array}$ & $\begin{array}{l}3,120 \\
3,280\end{array}$ & $\begin{array}{l}1,850 \\
1,610\end{array}$ & $\begin{array}{l}50 \\
60\end{array}$ & $\begin{array}{l}.59 \\
.49\end{array}$ & $\begin{array}{l}.59 \\
.59\end{array}$ & $\begin{array}{r}0.12 \\
.14\end{array}$ & $\begin{array}{l}25 \\
36\end{array}$ & $\begin{array}{l}8 \mathrm{~s} \\
2 \mathrm{C}\end{array}$ & $\begin{array}{r}.88 \\
.89\end{array}$ \\
\hline $\begin{array}{l}10 / 9 \\
10 / 11 \\
10 / 12 \\
10 / 13 \\
10 / 17 \\
10 / 25 \\
10 / 26\end{array}$ & $\begin{array}{l}49.1 \\
65.8 \\
63.6 \\
69.9 \\
43.0 \\
63.0 \\
59.0\end{array}$ & $\begin{array}{l}2,280 \\
3,750 \\
3,490 \\
3,980 \\
3,580 \\
3,090 \\
2,600\end{array}$ & $\begin{array}{l}1,590 \\
1,970 \\
1,980 \\
1,660 \\
1,670 \\
1,730 \\
1,440\end{array}$ & $\begin{array}{l}55 \\
60 \\
60 \\
60 \\
55 \\
50 \\
60\end{array}$ & $\begin{array}{l}.48 \\
.53 \\
.55 \\
.42 \\
.47 \\
.56 \\
.56\end{array}$ & $\begin{array}{l}.63 \\
.67 \\
.57 \\
.67 \\
.68 \\
.62 \\
.57\end{array}$ & $\begin{array}{l}.07 \\
.07 \\
.07 \\
.04 \\
.08 \\
.04 \\
.10\end{array}$ & $\begin{array}{r}34 \\
130 \\
32 \\
140 \\
90 \\
50 \\
59\end{array}$ & $\begin{array}{l}\text { A } 12 \\
\text { × } 8 \\
\text { \& } 10 \\
\text { \& } 10 \\
\text { \& } 10 \\
\text { \& } 10 \\
\text {. } 10\end{array}$ & $\begin{array}{l}.88 \\
.75 \\
. .87 \\
\therefore .77 \\
.80 \\
.84 \\
.82\end{array}$ \\
\hline $11 / 16$ & 61.0 & 3,660 & 1,650 & 65 & .45 & .62 & .11 & 91 & 35 & .93 \\
\hline Average.. & ….... & 3,320 & 1,810 & 58 & 0.55 & 0,61 & 0.081 & & $=10$ & * 0.82 \\
\hline $\begin{array}{c}\text { Standard } \\
\text { devia- } \\
\text { tion. }\end{array}$ & & 110 & 85 & 1 & b 0.023 & 0.012 & 0.033 & & & 0.02 \\
\hline
\end{tabular}

- Only these values averaged.

- Omitting July 22,1938 , average $=0.53$; standard deviation $=0.016$.

In column 4 of table 1 is listed, for each sounding, the maximum observed counting rate obtained during the flight; and column 5 gives the average pressure, in millibars, observed at the time of maximum counting. Although the pressure could be read to the nearest 2 millibars, the pressure at the maximum counting rate could be estimated to only the nearest 5 millibars. The average value of the pressure at which the counting rate is a maximum is 58 millibars, which corresponds to an altitude of $69,500 \mathrm{ft}$. The percentage standard deviation of the values of column 4 from their average, 4.7 percent, is only slightly greater than for column 2, 3.3 percent. An increase of about this amount is not unexpected because of the increased uncertainties of measurement. It was hoped that by taking account of the differences in sensitivities of the various counters the deviations could be reduced. Accordingly, in column 6 are listed 
the ratios of the maximum counting rates of column 4 to the standard counting rates of column 3 . These ratios, with one exception, are noticeably more self-consistent than the maximum counting rates. Omitting the data of July 22, the percentage standard deviation of the ratios from their mean is less than 2 percent; including it the deviation is 4 percent. This one ratio is sufficiently out of line with the other 14 values to justify one of two conclusions, (1) something was wrong with the equipment, or (2) the cosmic-ray intensity at 60 millibars was abnormally high on July 22, 1938 . There was no obvious inadequacy in the performance of the equipment, as is evident by referring back to figure 10, which is the record of the flight for this date. On the other hand, an examination of records from other laboratories has shown no departures from normal on this date of either the cosmic-ray intensity at sea level, or magnetic or solar phenomena. Accordingly, there is no reason to choose one conclusion over the other.

In column 7 are shown the ratios of the maximum counting rates to the counting at 200 millibars. The consistency of the data of this column merely indicates that the curves for all flights, such as shown in figure 8 , had the same general shape. The agreement would probably be still better were it not for the facts (1), that counting rate was changing rapidly with time, and (2), that the counting time was extremely short. The data for 500 millibars, which are shown in column 8, are very erratic for not only are the counting rates varying and the counting period short, but the counting rate is low and appreciably influenced by the blank counting rate.

The blank counting rate represents the spontaneous discharge rate of the counter in the absence of radiation. It was determined by observing the counting rate in an iron shield of sufficient thickness to absorb gamma radiation and then subtracting from this value the number of counts expected from cosmic rays. Kolhörster and Janossy ${ }^{9}$ have estimated the cosmic-ray intensity at sea level as 0.6 particle per $\mathrm{cm}^{2}$ per minute, which value gives 19 counts per minute for our counters. This counting rate was then subtracted from the counting rates observed in the iron shield, and the remainder corresponds to the blank counting rates listed in column 9 of the table 1 .

The minimum pressure attained in each flight is listed in column 10 , and the ratio of counting rate at this pressure to the maximum counting rate is given in column 11 . The minimum pressures recorded in nine of these flights differ by no more than the precision of reading, so the counting rates at minimum pressure have been averaged for these flights. This gives a counting rate at 10 millibars equal to 0.82 percent of the maximum counting rate. The very low counting rate obtained in one high-altitude flight in our earlier work has not been repeated, so it is probable that the earlier data were erratic.

Inasmuch as the barometric capsules showed uncertainties as large as \pm 2 millibars during calibration, the error at 10 millibars may be as large as \pm 20 percent. The altitude corresponding to 10 millibars is approximately $101,000 \mathrm{ft}$, and the uncertainty in reading the barograph means that the actual altitude attained may differ from this figure by approximately $\pm 5,000 \mathrm{ft}$.

An estimate of the ratio of the maximum cosmic-ray intensity to sea-level intensity can be obtained by making use of the data of

I. Physik 93, 119 (1935). 
Kolhörster and Janossy referred to above. These data gave a sealevel counting rate of 19 for our counters, which is one ninety-fifth of the average value of the maximum counting rate, 1,810 per minute. This ratio is not directly comparable to similar ratios obtained by ionization chambers because of the directional effect of the counters. At sea level, where the cosmic rays are predominantly vertical, the effective area of the counters is essentially the product of the length and diameter. At high altitudes, however, observations such as those made in the stratosphere balloon Explorer $I I^{10}$ have shown the vertical and horizontal components to be nearly equal. With such a directional distribution the average effective area of the counters used in our work has been found by integration to be very nearly 50 percent of the effective area to vertical radiation. This means that the ratio of our maximum count to ground count-that is, 95should be approximately one-half the same ratio obtained by ionization-chamber measurements.

In the standardization of the counters with gamma radiation the radium was placed in the plane of the axis of the counters and at right angles to their axis, so that the effective area exposed to the gamma radiation was approximately one-half the effective area for vertical radiation or very nearly the same as the effective area to nondirectional radiation. Because of this it is believed that a reliable estimate of the maximum cosmic-ray intensity has been obtained by use of the standardized counters. This gives, as previously shown, a maximum counting rate equivalent to $0.54 \mathrm{mg}$ of radium at a distance of $1 \mathrm{~m}$.

Washington, August 8, 1939.

10 W. F. G. Swann, O. L. Locher, and W. E. Danforth, Phys. Rev. 51, 389 (1937). 